\title{
Adaptation and Validation of an Oral Anticoagulation Measurement of Treatment Adherence Instrument
}

\author{
Ariana Rodrigues da Silva Carvalho ${ }^{1}$ \\ Rosana Aparecida Spadoti Dantas² \\ Flávia Martinelli Pelegrino ${ }^{3}$ \\ Inaiara Scalçone Almeida Corbi ${ }^{4}$
}

This methodological study adapted and analyzed the psychometric properties of the Measurement of Treatment Adherence (MTA) instrument for Brazilian users of oral anticoagulation therapy. Its final version was tested with 178 individuals. The average of answers for all questions ranged from 4.6 to 5.8 and $97.2 \%$ of the individuals were considered adherent. Moderate correlations were obtained between the adherence measure and the Mental health and Vitality domains of the SF-36. Cronbach's alpha was 0.60 and the ceiling effect occurred in answers to all items. These results indicate weak evidence of the validity, reliability and responsiveness of the MTA-adapted version for users of oral anticoagulant therapy.

Descriptors: Validation Studies; Psychometrics; Anticoagulants; Questionnaires; Medication Adherence.

\footnotetext{
${ }^{1}$ RN. Doctoral Student in Nursing, Escola de Enfermagem de Ribeirão Preto, Universidade de São Paulo, WHO Collaborating Centre for Nursing Research Development, SP, Brazil. Faculty, Universidade Estadual do Oeste do Paraná (Unioeste), Campus Cascavel, PR, Brazil. E-mail: mauroari2@hotmail.com.

${ }^{2}$ RN, Associate Professor, Escola de Enfermagem de Ribeirão Preto, Universidade de São Paulo, WHO Collaborating Centre for Nursing Research Development, SP, Brazil. E-mail: rsdantas@eerp.usp.br.

${ }^{3}$ RN, M.Sc. in Nursing. E-mail: flavia-martinelli@bol.com.br.

${ }^{4}$ RN, M.Sc. in Nursing. Faculty, Universidade Paulista (UNIP), Campus Araraquara, SP, Brazil. E-mail: inaenf@yahoo.com.br.
}

Corresponding Author:

Rosana Aparecida Spadoti Dantas

Universidade de São Paulo. Escola de Enfermagem de Ribeirão Preto

Av. Bandeirantes, 3900

Bairro: Monte Alegre

CEP: 14040-902 Ribeirão Preto, SP, Brasil

E-mail: rsdantas@eerp.usp.br 


\section{Adaptação e validação de uma medida de adesão à terapia de anticoagulação oral}

Este é um estudo metodológico que teve como objetivos adaptar e analisar as propriedades psicométricas do instrumento medida de adesão aos tratamentos (MAT) como medida de adesão à terapêutica de anticoagulação oral (ACO). A versão final foi testada em 178 sujeitos. As médias das respostas aos itens do MAT variaram de 4,6 a 5,8, sendo que $97,2 \%$ foram considerados aderentes. Correlações moderadas foram obtidas entre a medida de adesão e os domínios saúde mental e vitalidade, do SF-36. O alfa de Cronbach obtido foi 0,60 e constatou-se a presença de efeito máximo nas respostas de todos os itens. Esses resultados indicam fracas evidências da validade, confiabilidade e responsividade da versão adaptada do MAT para usuários de anticoagulantes orais.

Descritores: Estudos de Validação; Psicometria; Anticoagulantes; Questionários; Adesão ao Medicamento.

\section{Adaptación y validación de una medida de adhesión a la terapia de anticoagulante oral}

Este es un estudio metodológico que tuvo como objetivos adaptar y analizar las propiedades psicométricas del instrumento medida de adhesión a los tratamientos (MAT) como medida de adhesión a la terapéutica de anticoagulante oral (ACO). La versión final fue probada en 178 sujetos. Los promedios de las respuestas a los ítems del MAT variaron de 4,6 la 5,8, siendo que 97,2\% fueron considerados adherentes. Correlaciones moderadas fueron obtenidas entre la medida de adhesión y los dominios salud mental y vitalidad, del SF-36. El alfa de Cronbach obtenido fue 0,60 y se constató la presencia de efecto máximo en las respuestas de todos los ítems. Eses resultados indican débiles evidencias de la validad, confiabilidad y responsividad de la versión adaptada del MAT para usuarios de anticoagulantes orales.

Descriptores: Estudios de Validación; Psicometría; Anticoagulantes; Cuestionario; Adhesión al Tratamiento.

\section{Introduction}

Adherence can be defined as the level of agreement between the recommendations of the healthcare provider and the individual's behavior in relation to the therapeutic regimen ${ }^{(1)}$. There are several factors influencing nonadherence to the pharmacological treatment, such as: factors related to the patient, disease, treatment, health services and social support(2). Brazilian research on the subject related to medication adherence is common among individuals using antiretroviral, anti-hypertensive and anti-diabetic (hypoglycemic) medications, however, it is incipient among individuals using oral anticoagulant therapy (OAT). Adherence to OAT is one of the important factors in achieving an optimum level of anticoagulation in order to avoid bleeding and thromboembolic complications among patients. Additionally, its misuse under-dosing or overdosing - whether by forgetfulness or human error, can also pose risk to health, increasing the chances of bleeding or thromboembolic events, since the therapy goals are not being $\operatorname{met}^{(3)}$.

Research addressing the management of OAT has indicated some factors that can affect the control of this therapy, such as: clinical factors (e.g. acute disease, drug interactions, changes in diet), genetic factors and psychosocial factors (e.g. depression, cognitive disorder and one's perceived health condition)(3). There are practical and psychological requirements for OAT to be successful. These requirements may positively or negatively affect an individual's perception of health and quality of health ${ }^{(4)}$. 
The potential effects of inadequate adherence to OAT and risk factors that influence treatment adherence among patients are known, however, these effects and the best methods to evaluate them have not been well

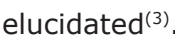

One of the difficulties found by researchers in evaluating medication adherence is the lack of valid, reliable, user-friendly and low-cost instruments in Brazil and worldwide, which hinders the comparison of results of different therapies and between distinct health services.

The best known and most used instrument for evaluating medication adherence is the MoriskiGreen questionnaire(5-6). Another proposed adherence instrument is the Measurement of Treatment Adherence ${ }^{(1)}$ (MTA), which was elaborated and tested among Portuguese diabetics and hypertensive individuals ${ }^{(1)}$. It was already validated in Brazil among a population of diabetic individuals and obtained satisfactory results(7). This study aimed to adapt and analyze the psychometric proprieties of the MTA instrument for Brazilians undergoing oral anticoagulant therapy concerning the instrument's validity (face, content and construct), reliability (internal consistency) and responsiveness in detecting changes.

\section{Casuistic and Method}

\section{Design, casuistic and ethical aspects}

This is a methodological study to adapt and validate the $M T A^{(1)}$ instrument, in a sample of anticoagulated individuals in Brazil. It was initiated after consent of the authors of the original version of the instrument was obtained. For its adaptation and validation, the original instrument was evaluated in terms of face and content validity by an expert committee and submitted to semantic analysis by individuals using OAT. The adapted version was tested on 178 individuals randomly approached while they were waiting for their appointment at the oral anticoagulation outpatient facility of a school hospital in the interior of São Paulo state, Brazil. The following inclusion criteria were considered: being 18 years old or older; following-up at the outpatient due to the use of OAT regardless of duration of use; showing cognitive ability to answer the instrument's questions. The project was approved by the Research Ethics Committee at the institution and authorization to access the patients' files was granted. All the individuals who agreed to participate in the study signed a free and informed consent form.

\section{Data Collection}

The individuals answered the $\mathrm{MTA}^{(1)}$ instrument adapted for Brazilians using oral anticoagulation and the Medical Outcomes Study 36 - Item Short-Form Health Survey ${ }^{(8)}$ (SF-36) adapted to Portuguese ${ }^{(9)}$. The individuals' sociodemographic and clinical data were collected through individual interviews and consulting their medical files.

\section{Instruments: Measurement of Treatment} Adherence (MTA)

MTA is composed of seven items that evaluate the individuals' behavior in relation to the daily use of medication (1), while some items were adapted from other authors (Items 1, 2, 3 and $4^{(5)}$, Item $6^{(10)}$ and Item $\left.7^{(11)}\right)$. Answers were obtained using a six-point ordinal scale varying from always (1) to never (6). The scores obtained with answers to the seven items are summed and divided by the number of items, varying from one to six. Afterwards, the values 5 and 6 are computed as one (which in the original scale corresponds to adherence) and the remaining are computed as zero (non-adherence) ending up with a dichotomous scale: adherent/non-adherent.

\section{Medical Outcomes Survey Short Form 36-items (SF-36)}

This multidimensional questionnaire evaluates an individual's perceived health status and is composed of 36 items that cover eight components or domains: Physical functioning (10 items), Role physical (four), Bodily pain (two), General health (five), Vitality (four), Social functioning (two), Role emotional (three), Mental health (five) and another question to compare the evaluation of current health status with that of one year ago. The scores of each of the domains are normalized on a scale from 0 to 100 , in which low numbers indicate worse perceived health status ${ }^{(8)}$. The SF-36 evaluates the individual's perception of disease and/or treatment in various aspects of life and has been used in the investigation of individuals in oral anticoagulation treatment ${ }^{(3-4)}$.

\section{MTA Adaptation and validation process}

The original version was submitted to face and content validity by a committee of experts and to semantic analysis by seven individuals using OAT. The experts (four nurses and one physician, all experts in cardiology) were asked to evaluate the relevance and 
clarity of each item so that each would meet the study's objectives. The experts made semantic adaptations from the Portuguese of Portugal to Brazilian Portuguese, so the instrument's use would be appropriate to Brazilian individuals. This version was submitted to semantic analysis, which revealed to the authors that the patients' answers concerned medication used, not specifically focusing on the OAT. When patients were asked about it, they confirmed that the MTA questions did not lead them to focus on their oral anticoagulation therapy only, but on all medication they were using. Thus, the researchers changed the wording of questions and adapted them to users of oral anticoagulant therapy, replacing the word medication with oral coagulant and adding some information related to OAT such as in questions 4, 5 and 7, with a view to clarify for individuals the potential complications related to the use of OAT (e.g. increased menstrual flow, bruises, blood in urine or feces, bleeding gums) and also related to reasons that could lead them not to take the medication (not having the medication at home or at another place, not having money, running out of medication or not being able to buy the medication or, the medication is not available at the drugstore or at the basic health unit). These changes aimed to clarify the MTA items to patients using OAT. The scale was not altered since it was considered appropriate both by the judges and participants, thus the original version $^{(1)}$ was maintained.

\section{Data analysis}

We assumed strong and moderate correlations between adherence measures (MTA) and health status (SF-36) in order to analyze the convergent construct validity. Spearman's correlation test was performed and the results were analyzed according to the following classification: scores below 0.30 have little clinical applicability even when statistically significant, scores between 0.30 and 0.50 are moderate and above 0.50 have a strong magnitude(12). The level of significance adopted in this study was 0.05 . The instrument reliability evaluated through the internal consistency of the MTA items was verified by Crombach's alpha, considering appropriate scores between 0.70 and $0.90^{(13)}$. It is worth noting that some high alpha values are usually found in scales with many items due to the fact the alpha depends on the number of items in the scale. This same dependency can happen with instruments with few items, such as MTA. In this case, an alpha value around 0.50 is acceptable ${ }^{(14)}$. The instrument's responsiveness was verified with the presence of ceiling and floor effects in the studied samples. An instrument responsiveness test reports its capacity to detect changes, for example, when the individual improves or worsens ${ }^{(15)}$; it refers to the instrument's ability to detect clinically important changes over time ${ }^{(16)}$. The ceiling and floor effects are taken into account when respondents chose the highest or lowest scores, respectively, in the scale. Hence, if these effects are present it is likely that answers are at the beginning or at the end of the scale, which indicates limited content validity. As a consequence, individuals with the lowest or the highest scores cannot be discriminated and the instrument responsiveness is reduced. The floor effect (low adherence) was considered when more than $15 \%$ of respondents opted for answer number 1 and the ceiling effect when more than $15 \%$ opted for the answer with score $6^{(16)}$.

\section{Results}

Among the 178 participants, 116 (65.3\%) were women. The average age was 55.6 years (interval from 24.8 to 86.1 ), $60 \%$ of them were younger than 60 years old. The majority reported not completing primary school (126 - 70.8\%), average family income was $\mathrm{R} \$ 896^{*}$ (interval from $\mathrm{R} \$ 300$ to $\mathrm{R} \$ 4,500)$, married/consensual union $(118-65.2 \%)$, white $(115-63.9 \%)$, retired $(65-$ $36.7 \%)$, from Ribeirão Preto and other cities in the state of São Paulo, Brazil (148-83.2\%). The main indications for the use of OAT were: artificial heart valve (50.6\%) and atrial fibrillation (33.1\%), followed by thrombus in the ventricle $(8.4 \%)$, pulmonary thromboembolism $(2.2 \%)$, stroke $(2.2 \%)$, acute myocardial infarction $(1.1 \%)$, pacemaker $(1.1 \%)$ and deep vein thrombosis $(0.6 \%)$. The participants also used other medications such as: anti-hypertensives (116-65.2\%), diuretics (99 - 55.6\%), beta blockers $(74-43.7 \%)$, followed by other groups of medications $(127-71.3 \%)$. In relation to the number of medications, $85(49.4 \%)$ of the individuals used from three to five medications, 43 (25\%) used up to two medications and $44(25.6 \%)$ participants used six or more, varying from one to 12 , with an average of four medications per individual. This information was not available in the medical files of six participants.

In relation to the descriptive analysis of the MTA adapted version, the total scale and each one of the items, an average value of 5.5 ( $s d=0.45$ ) was obtained for the total measure and average values between 4.6 and 5.9 for the items. We observe that six of the seven items presented a median of six, which corresponds to the score related to the answer "Never", though the scores intervals also

\footnotetext{
* N.T. USD 509 in March 2010.
} 
comprehended lower scores, that is, the scores one and two (Table 1). The obtained answers were summed and the values divided by the instrument's number of items (possible interval from 1 to 6 ). Afterwards, the scores 5 and 6 were computed as one (which in the original scale corresponds to adherent) and the remaining ones were computed as zero (non-adherent in the original scale). After this categorization, 173 $(97.2 \%)$ individuals were classified as adherent and only five $(2.8 \%)$ as non-adherent.

Table 1 - Descriptive analysis of the adapted version of the MTA instrument in 178 patients undergoing oral coagulation treatment.

\begin{tabular}{|c|c|c|c|}
\hline MTA adapted version & Average (sd) & Median & $\begin{array}{c}\text { Obtained } \\
\text { Interval }\end{array}$ \\
\hline Total scale & $5.5(0.4)$ & 5.7 & $3.4-6$ \\
\hline \multicolumn{4}{|l|}{ Items } \\
\hline How often did you forget to take the anticoagulant? & $5.3(0.9)$ & 6 & $1-6$ \\
\hline How often did you take the anticoagulant outside of the scheduled time? & $4.6(1.6)$ & 5 & $1-6$ \\
\hline How often did you stop taking the anticoagulant because you felt better? & $5.9(0.5)$ & 6 & $2-6$ \\
\hline How often did you stop taking the anticoagulant because you felt worse? & $5.7(0.8)$ & 6 & $1-6$ \\
\hline How often did you change the anticoagulant dose because you forgot to take it the day before? & $5.8(0.6)$ & 6 & $1-6$ \\
\hline How often did you not take the anticoagulant because you ran out of it? & $5.7(0.7)$ & 6 & 2-6 \\
\hline How often did you not take the anticoagulant for reasons beyond your control? & $5.8(0.5)$ & 6 & 4-6 \\
\hline
\end{tabular}

The descriptive analysis of items permitted evaluating the responsiveness of the MTA adapted version among individuals using OAT, verified by the presence of ceiling and floor effects in the studied sample. As the medians of the participants' answers indicated (Table 1 ), we observe in Table 2 that the frequencies of answers for each question of the instrument are above $15 \%$ for the answer "Never" (score six), which corresponds to the best evaluation for adherence (ceiling effect). The highest frequency of this answer is found in the question How often did you stop taking the anticoagulant because you felt better? (92.7\%) and the lowest was found in the question How often did you take the anticoagulant out of the scheduled time? (37.6\%).

Table 2 - Distribution of the percentage of answers to questions of the MTA adapted version, of 178 patients undergoing oral coagulant therapy.

\begin{tabular}{|c|c|c|c|c|c|c|}
\hline Questions & Always & $\begin{array}{l}\text { Almost } \\
\text { always }\end{array}$ & Frequently & Sometimes & Rarely & Never \\
\hline How often did you forget to take the anticoagulant? & $0.6 \%$ & $0.6 \%$ & $1.1 \%$ & $16.3 \%$ & $27.5 \%$ & $53.9 \%$ \\
\hline How often did you take the anticoagulant out of the scheduled time? & $10.1 \%$ & $4.5 \%$ & $2.8 \%$ & $21.9 \%$ & $23 \%$ & $37.6 \%$ \\
\hline $\begin{array}{l}\text { How often did you stop taking the anticoagulant because you felt } \\
\text { better? }\end{array}$ & - & $0.6 \%$ & $1.1 \%$ & $1.7 \%$ & $2.2 \%$ & $94.4 \%$ \\
\hline $\begin{array}{l}\text { How often did you stop taking the anticoagulant because you felt } \\
\text { worse? }\end{array}$ & $1.1 \%$ & $0.6 \%$ & - & $7.3 \%$ & $4.5 \%$ & $86.5 \%$ \\
\hline $\begin{array}{l}\text { How often did you change the anticoagulant dose because you forgot } \\
\text { to take it the day before? }\end{array}$ & $0.6 \%$ & $1.1 \%$ & - & $1.7 \%$ & $3.9 \%$ & $92.7 \%$ \\
\hline How often did you not take the anticoagulant because you ran out of it? & - & $1.1 \%$ & - & $5.1 \%$ & $14 \%$ & $79.8 \%$ \\
\hline $\begin{array}{l}\text { How often did you not take the anticoagulant for reasons beyond } \\
\text { your control? }\end{array}$ & - & - & - & $3.4 \%$ & $10.1 \%$ & $86.5 \%$ \\
\hline
\end{tabular}

The validity of the convergent construct was verified by the correlation of the adherence measure with the measures of the SF-36 domains. Both scales are ordered in such a way that higher scores indicate a higher level adherence and better evaluation of perceive health status. The Spearman's correlation coefficients between measures are presented in Table 3. Moderate and statistically significant correlations were observed only between the adherence measure and the domains of Mental health $(r=0,318 ; p<0.001)$ and Vitality $(r=0.305 ; p<0.001)$. Although statistically significant, the correlations of adherence with the domains of Bodily pain, General Health and Social functioning were below 0.30 and of no clinical relevance. 
Table 3 - Spearman's correlation coefficients between adherence measures (MTA) and general health status (SF-36 domains) according to the answers of 178 patients undergoing oral anticoagulant therapy.

\begin{tabular}{lcc}
\hline \multicolumn{1}{c}{ SF-36 Domains } & $\mathbf{r}$ & $\mathbf{p}$ \\
\hline Mental Health & 0.318 & $<0.001$ \\
Vitality & 0.305 & $<0.001$ \\
Bodily pain & 0.198 & $<0.05$ \\
General health & 0.164 & $<0.05$ \\
Social functioning & 0.164 & $<0.05$ \\
Role emotional & 0.121 & $>0.05$ \\
Physical capacity & 0.102 & $>0.05$ \\
Role physical & 0.078 & $>0.05$ \\
\hline
\end{tabular}

Cronbach's alpha value concerning the reliability of the MTA adapted version was 0.60. This value varies downward when each item of the instrument is drawn, varying from $\alpha=0.47$ (when the first question is deleted) to $\alpha=0.59$ (when questions 2 and 4 are deleted). The correlations of each item with the total scale (without the correlated item) were moderate for the MAT questions, except for the question 4, whose value was 0.11 (Table 4).

Table 4 - Analysis of the reliability of the MAT adapted version for the 178 patients undergoing oral coagulation therapy.

\begin{tabular}{|c|c|c|}
\hline & $\begin{array}{l}\text { Item-total } \\
\text { Correlation }\end{array}$ & $\begin{array}{c}\text { Cronbach's } \\
\text { alpha when } \\
\text { item was } \\
\text { excluded }\end{array}$ \\
\hline $\begin{array}{l}\text { Q1. How often did you forget to take the } \\
\text { anticoagulant? }\end{array}$ & 0.43 & 0.47 \\
\hline $\begin{array}{l}\text { Q2. How often did you take the } \\
\text { anticoagulant out of the schedule time? }\end{array}$ & 0.32 & 0.59 \\
\hline $\begin{array}{l}\text { Q3. How often you did you stop taking } \\
\text { the anticoagulant because you felt } \\
\text { better? }\end{array}$ & 0.35 & 0.52 \\
\hline $\begin{array}{l}\text { Q4. How often did you stop taking the } \\
\text { anticoagulant because you felt worse? }\end{array}$ & 0.11 & 0.59 \\
\hline $\begin{array}{l}\text { Q5. How often did you change the } \\
\text { anticoagulant dose because you had } \\
\text { forgot to take it the day before? }\end{array}$ & 0.32 & 0.52 \\
\hline $\begin{array}{l}\text { Q6. How often did you not take the } \\
\text { anticoagulant because you run out of it? }\end{array}$ & 0.48 & 0.47 \\
\hline $\begin{array}{l}\text { Q7. How often did you not take the } \\
\text { anticoagulant for reasons beyond your } \\
\text { control? }\end{array}$ & 0.34 & 0.53 \\
\hline
\end{tabular}

\section{Discussion}

This study adapted the Measurement of Treatment Adherence for oral coagulant users and tested its validity (face, content and construct), reliability and responsiveness. As in the original study ${ }^{(1)}$ and in the study of adaptation of the instrument for Brazil(7), patients who participated in the validation of the instrument in this study were predominantly adult, women, with low level of education, and used multiple medications to treat chronic conditions.

The items composing the MTA were considered relevant for the evaluation of OAT adherence considering the face and content validity of the adapted instrument evaluated by the judges. This judgment reinforces the proposal of authors ${ }^{(1)}$ to enlarge the original measure of four items ${ }^{(5)}$ including questions that address nonadherence behaviors due to excess of prescriptions (Item 5), situations that can lead to the interruption of the treatment due to economic reasons or other reasons (Item 6) and reasons that lead to the treatment interruption other than medical indications (Item 7).

In regard to the results of the adapted instrument for OAT, an average of 5.5 ( $\mathrm{sd}=0.4$ ) was found for the total of seven items with an interval of 3.4 to 6 . These results were similar to those obtained in the original version(1). The evaluation of the convergent construct validity of the MTA adapted version between individuals using the OAT was verified by the correlation of the adherence measure with the measures of the SF-36 domains and presented statistically significant moderated correlations only between the adherence measure and the mental health and vitality domains. No other authors evaluated the validity of the MTA construct using this measure of perceived health status. The validity of concurrent criterion has been used associating the adherence measure evaluated by the Likert scale for the seven MTA items with counting of medications ${ }^{(1)}$. This validity was not investigated in this study due to the difficulty of counting the medications among patients cared for in the outpatient clinic. Return visits could not be scheduled due to a lack of time for patients to bring their medications to be counted by the researchers.

The instrument's internal consistency measured by Cronbach's alpha was 0.6, a value that can be considered appropriate given the instrument's small number of items ${ }^{(14)}$. This value is similar to those found in studies that use adherence measures of four items ${ }^{(5)}$ 
and dichotomous items ${ }^{(17)}$, which obtained alpha values of 0.61 and 0.54 respectively. We observe that the inclusion of another item, even a dichotomous one, raised the alpha value to 0.71 in another study ${ }^{(11)}$, which did not occur when the MTA with seven items were tested with dichotomous answers (alpha of 0.54$)^{(1)}$. Hence, we considered that the value 0.60 obtained in the sevenitem version did not achieve the result obtained in the original MTA version using the Likert scale (alpha of 0.74 ) but was a little higher than that obtained with the dichotomous response scale. When the alpha value was tested in the original study ${ }^{(1)}$, considering the successive withdrawn of each one of the MTA items, amplitude from 0.69 to 0.73 was obtained, while amplitude from 0.47 to 0.59 was found in this study. The values of the correlations between item-total also differed in the two studies: 0.11 to 0.48 for individuals using OAT and 0.37 to 0.56 for the Portuguese individuals ${ }^{(1)}$.

The instrument responsiveness was tested by the presence of ceiling and floor effects and a percentage larger than $15 \%$ was obtained in all questions for the alternative "Never", which corresponds to the largest score and highest adherence on the scale. Hence, evidence of the ceiling effect suggests that the instrument does not allow detecting changes in individuals in relation to OAT adherence ${ }^{(16)}$. Studies that evaluated the responsiveness through the presence of these effects were not found either. According to the instrument, $97.2 \%$ of the individuals were classified as adherent to their OAT. The percentage of adherence was higher than the results described in the Portuguese study ${ }^{(1)}$ and by those who tested the instrument in Brazil(7), $61.6 \%$ and $78.3 \%$ respectively. Some hypotheses were considered to explain this higher percentage such as the inexistence of side effects such as those caused by antihypertensive and oral hypoglecemiants, accounting for the difference in the results obtained in other studies ${ }^{(1,7)}$. The low percentage of non-adherent individuals $(2.8 \%)$ hindered comparison between the two groups to test the adapted version's sensitivity so as to perceive differences between the groups.

This study presents weak evidence to confirm the psychometric properties of the instrument when adapted to individuals using OAT. However, given the results obtained by the original MTA version in other $\operatorname{studies}^{(1,7)}$, we suggest further research to evaluate the construct validity, criterion, reliability and responsiveness of the version adapted for individuals using OAT, who present other sociodemographic profiles or higher educational or income levels.

\section{Conclusions and Final Considerations}

This initial study aimed to adapt the Measurement of Treatment Adherence instrument proposed as a general measure of pharmacological adherence exclusively in regard to the use of oral anticoagulant therapy. The results obtained were sufficient to confirm the validity and reliability of the adapted version when used for individuals using this therapy. We suggest further research with patients with diversified sociodemographic and clinical characteristics using oral anticoagulant therapy as well as further research concomitantly using other adherence measures such as the counting of medications, electronic monitoring and other self-report instruments.

\section{References}

1. Delgado AB, Lima ML. Contributo para validação concorrente de uma medida de adesão aos tratamentos. Psicologia, Saude \& Doenças 2001; 2(2):81-100

2. Colombrini MRC, Coleta MFD, Lopes MHBM. Fatores de risco para não-adesão ao tratamento com terapia antiretroviral altamente eficaz. Rev Esc Enferm USP 2008; 42(3):490-5.

3. Platt $A B$, Localio $R$, Brensinger CM, Cruess DG, Christie JD, Gross R, et al. Risk factors for nonadherence to warfarin: results from the IN-RANGE study. Pharmacoepidemiol Drug Safety. 2008; 17:853-60.

4. Casais $P$, Meschengieser SS, Sanchez-Luceros A, Lazzari MA: Patients' perceptions regarding oral anticoagulation therapy and its effect on quality of life. Curr Med Res Opin 2005; 21:1085-90.

5. Morisky DE, Levine DM, Green LW, Smith CR. Health education program effects on the management of hypertension in the elderly. Arch Intern Med. 1982; 142(10):1835-8.
6. Morisky DE, Green LW, Levine M. Concurrent and predictive validity of a self-reported measure of medication adherence. Med Care. 1986; 24:67-74.

7. Gimenes HT, Zanetti ML, Haas VJ. Factors related to patient adherence to antidiabetic drug therapy. Rev. Latino-Am. Enfermagem. 2009 janeiro-fevereiro; 17(1):46-51.

8. Ware Jr JE, Sherbourne CD. The MOS 36-item short-form health survey (SF-36). I. Conceptual framework and item selection. Med Care 1992; 30(6):473-83.

9. Ciconelli RM, Ferraz MB, Santos W, Meinão I, Quaresma MR. Tradução para língua portuguesa e validação do questionário genérico de avaliação de qualidade de vida SF-36. Rev Bras Reumatol. 1999; 39(3):143-50.

10. Ramalhinho I. Adesão à terapêutica anti-hipertensiva. Contributo para o seu estudo. Lisboa: Faculdade de Farmácia da Universidade de Lisboa; 1994. 
11. Shea S, Misra D, Ehrlich MH, Field L, Francis C K. Correlates of nonadherence to hypertension treatment in an inner-city minority population. Am J Public Health 1992; 12: 1607-12.

12. Ajzen I, Fishbein M. Understanding Attitudes and Predicting Social Behavior. Englewood Cliffs (NJ): Prentice Hall; 1998.

13. Nunnally JC, Bernstein IH. Psychometric theory. $3^{\text {rd }}$ ed. New York: McGraw-Hill; 1994.

14. Bowling A. Measuring health. A review of quality of life measurement scales. $3^{\text {rd }}$ ed. Philadelphia: Open University Press; 2005.
15. Fayers PM, Machin D. Quality of life. The assessment, analysis, and interpretation of patient-reported outcomes. $2^{\text {nd }}$ ed. Chichester: England John Wiley; 2007.

16. Terwee CB, Bot SDM, Boer MR, van der Windt DAWM, $\mathrm{Knol} \mathrm{DL}$, Dekker J, et al. Quality criteria were proposed for measurement properties of health status questionnaires. J Clin Epidemiol. 2007; 60:34-42.

17. Grégoire J, Guibert R, Archambault A, Contandriopoulus A. Medication compliance in a family practice. Can Fam Phys 1992; 38:2333-7. 